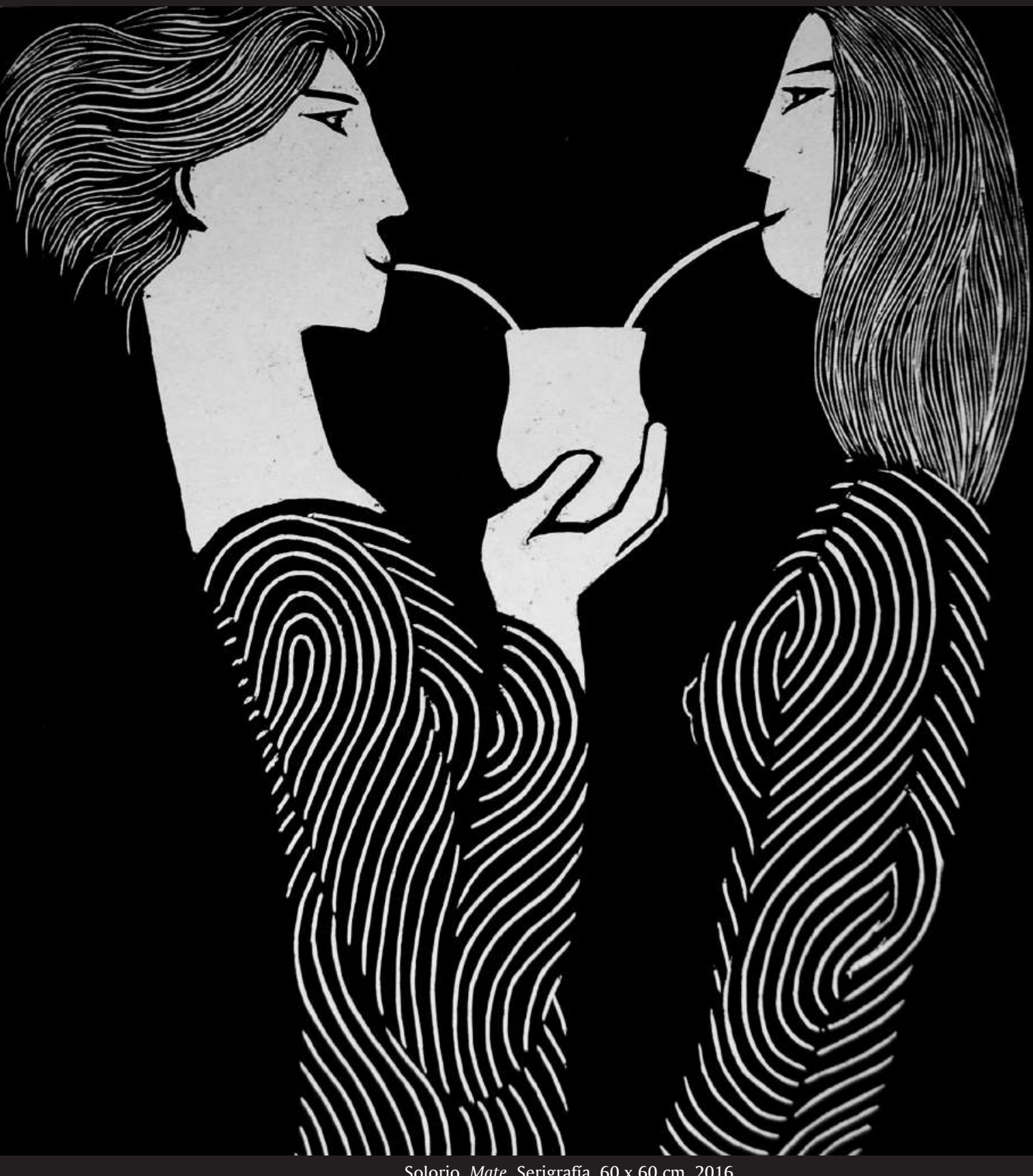




\title{
El grabado contemporáneo en Arequipa
}

\author{
Manuel Munive Maco \\ Investigador independiente \\ rupestrecontemporaneo@gmail.com
}

\begin{abstract}
Resumen
La ciudad de Arequipa, una de las más importantes del Perú, se ha caracterizado por ser tierra de acuarelistas, tal como lo deja ver la interminable nómina de virtuosos pintores que sustentan esta tradición plástica desde hace más de un siglo. Sin embargo, desde hace poco tiempo, y casi a la sombra de la acuarela, ha ido desarrollándose el trabajo de un grupo de artistas de distintas generaciones, que eligieron el grabado como medio de expresión. El presente trabajo propone una primera mirada de conjunto a este acervo gráfico.
\end{abstract}

Palabras clave: Arequipa, arte, tradición plástica, arte contemporáneo, grabado.

\begin{abstract}
The city of Arequipa, one of the most important cities in Peru, has been characterized as a land of watercolorists, as shown by the endless list of virtuous painters that sustains this visual arts tradition for more than a century. However, for a short time, and almost in the shadow of watercolor, the work of a group of artists from different generations has been developing engraving as a means of expression. This work proposes a first overview of this graphic collection.
\end{abstract}

Keywords: Arequipa, art, plastic tradition, contemporary art, engraving.

\section{Introducción}

Ciudades del Perú, como Arequipa, Trujillo, Cusco y Lima, solo por citar algunas de las más importantes, cuentan desde hace mucho tiempo con escuelas de formación artística estatales, la mayoría de ellas independientes y otras integradas a facultades universitarias. En todos estos centros, la enseñanza de la pintura y la escultura goza de una relativa buena salud, mientras que la del grabado se halla, en la mayoría de casos, en una permanente zozobra, lo que se percibe en el hecho de que este medio artístico se imparta solamente como un curso o taller, y no como una especialidad, condición merecida no solo por la diversidad y complejidad de las técnicas que la integran, sino por su evidente potencial comercial.

Esta inestabilidad de la enseñanza del grabado en nuestro país, a pesar de su importancia tanto para la creación contemporánea como por su entronque con el pasado del libro y la cultura, son probablemente las principales razones que me llevaron a seguir la trayectoria 


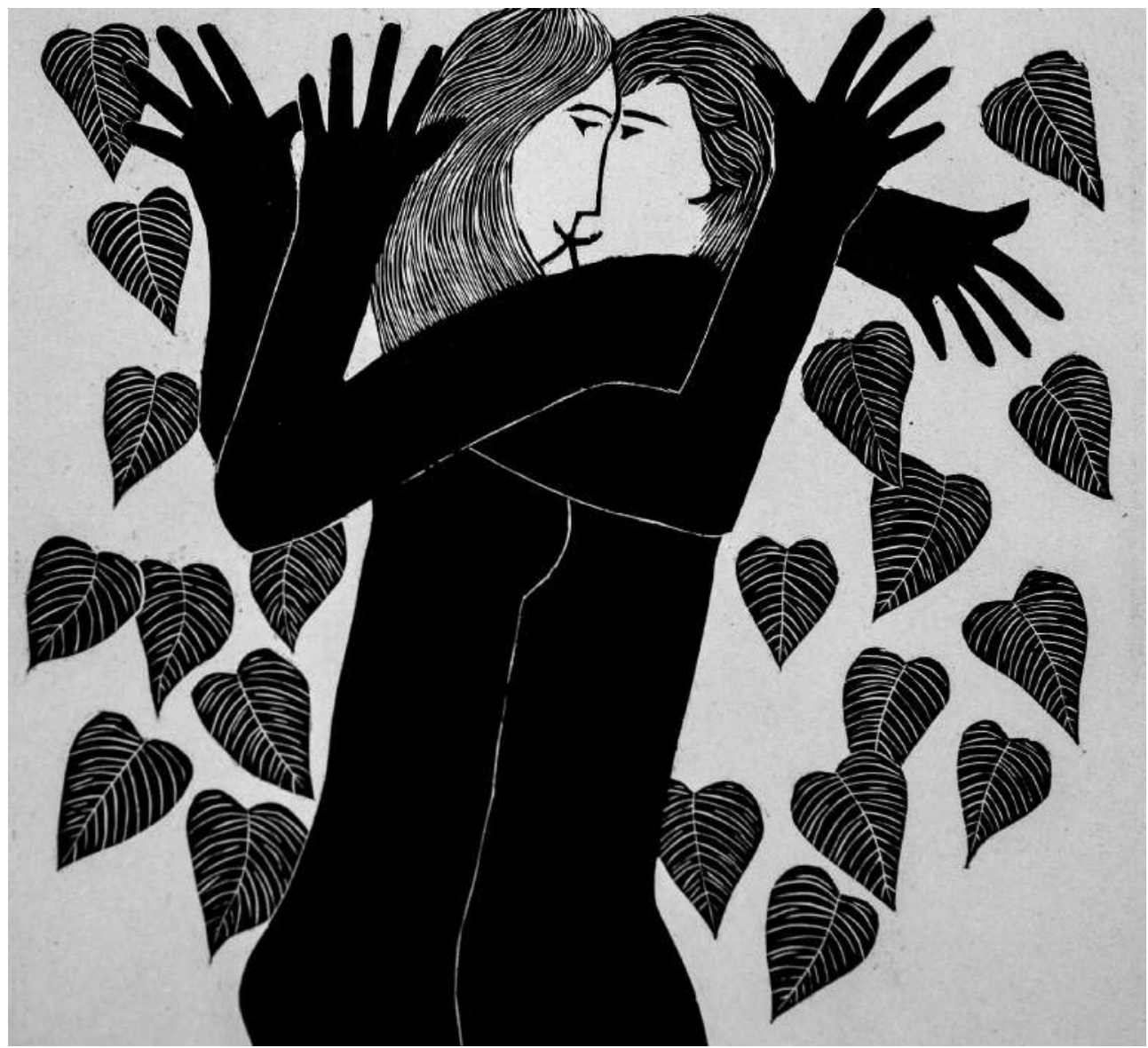

Solorio. Hojas de morera. Xilografía. 60 x 64 cm, 2016

de varios de los mejores grabadores peruanos ${ }^{1}$ para, en principio, aprender mediante su trabajo de ese noble arte y, posteriormente, revelarlo a través del único medio con el que un curador dispone para llegar al público de verdad: la exposición en una galería de libre acceso.

\section{El grabado más allá de Lima}

Existen coincidencias en la historia temprana de algunas de las escuelas de arte donde se enseña el grabado como curso, taller o especialidad. La primera, que fue crucial para su existencia, la participación de un grabador que, además de fundarlas y dedicarles lo más importante de su tiempo, la proveyó personalmente de su equipamiento primordial. Esto sucedió en el caso del Taller de Grabado de la Universidad de Bellas Artes "Diego Quispe Tito" del Cusco, que recibió como donación del artista y docente Abraham Cano Luza, una prensa litográfica que todavía se puede apreciar, ya fuera de uso, en una de sus aulas. De igual modo, el grabador Miguel Ángel Espinoza donó la prensa litográfica que trajo desde Chile al Taller de Grabado de la Escuela de Arte de la Universidad Nacional de San

1 Curiosamente, casi todos ellos, salvo una que otra excepción, se encuentran fuera de la enseñanza en nuestras escuelas; pero esa es otra historia, que trataremos tácitamente en los últimos párrafos. 
Agustín en Arequipa, una verdadera reliquia que permanece al lado de la prensa moderna que se encuentra en funcionamiento. Y en el caso del Taller de Grabado de la Escuela de Formación Artística Pública "Francisco Laso" de Tacna ocurrió algo similar: fue fundado por el artista y docente Jorge Ara, tacneño de nacimiento, quien además llevó la prensa que ahora se encuentra allí. Ara tuvo también una participación decisiva en la enseñanza del grabado en la Escuela Nacional de Bellas Artes y en la Pontificia Universidad Católica, ambas en Lima.

Por lo mencionado, tanto Cano como Espinoza y Ara, ya fallecidos, merecen que su obra sea divulgada y reconocida mediante exhibiciones itinerantes y publicaciones ilustradas que la estudien, destacando a la vez su rol fundacional de la disciplina en cada uno de sus contextos. Sé que en otras ciudades y escuelas existieron también otros grabadores que trabajaron denodadamente por la enseñanza y el ejercicio del arte de la multicopia, y cuyo trabajo debemos rastrear con urgencia, pues con el tiempo sus archivos y materiales se van dispersando en diversas manos o, en el peor de los casos, se pierden en bloque ante el total desinterés de sus herederos, como ocurrió, dolorosamente, con las estampas, matrices y documentos de Julio Camino Sánchez, un apasionado maestro de la xilografía, poco tiempo después de su fallecimiento.

Este trabajo, junto con otros publicados con anterioridad en periódicos, revistas y catálogos, pretende ir conformando un registro de la obra de los grabadores peruanos que trabajaron y trabajan en las diversas ciudades del país, con particular énfasis en aquellos que resultan particularmente desconocidos fuera de su círculo de acción.

\section{El grabado actual en Arequipa}

Hasta hace poco supuse que si alguna vez dedicaba una aproximación al quehacer plástico de la Ciudad Blanca, esta tendría que iniciarse hablando ineludiblemente del ejercicio de la acuarela y, tal vez, en última instancia, del grabado. Sin embargo, la reciente eclosión de artistas de diversas generaciones y con lenguajes muy personales que han encontrado en el grabado un medio de expresión cotidiana, me motivó a hacer este primer recuento ${ }^{2}$.

Sin embargo, antes de proseguir, debo advertir dos cosas:

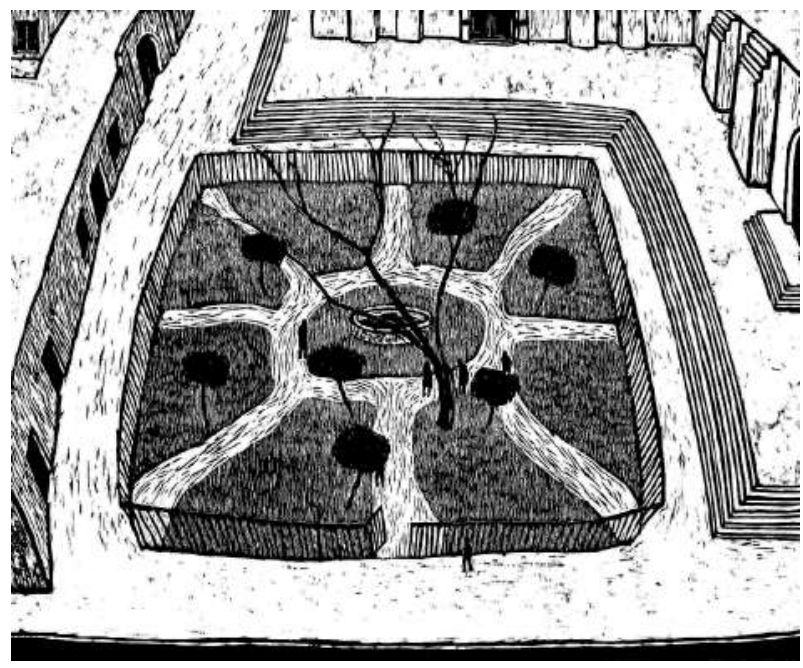

Lara. Parque San Francisco. Xilografía. 69.8 x 57.2 cm, 2014 primero, que si bien los artistas que enumeraré y reseñaré brevemente tuvieron una completa o parcial formación académica que pudo incluir el grabado, ha sido con posterioridad a esa experiencia que la mayoría redescubrió las posibilidades creativas de la obra impresa. En segundo lugar, añado que contrariamente a lo que pensé, es posible generar un movimiento genuino de artistas fuera de las instituciones "oficiales" de formación académica, lo que constituye algo digno de

2 Esa misma efervescencia fue la que motivó la muestra que, bajo el mismo título que este artículo, reunió una selección de estampas que se expusieron en el museo "Casa de la Xilografía” en Campos do Jordao, Sao Paulo, Brasil, entre junio y agosto del 2018. 


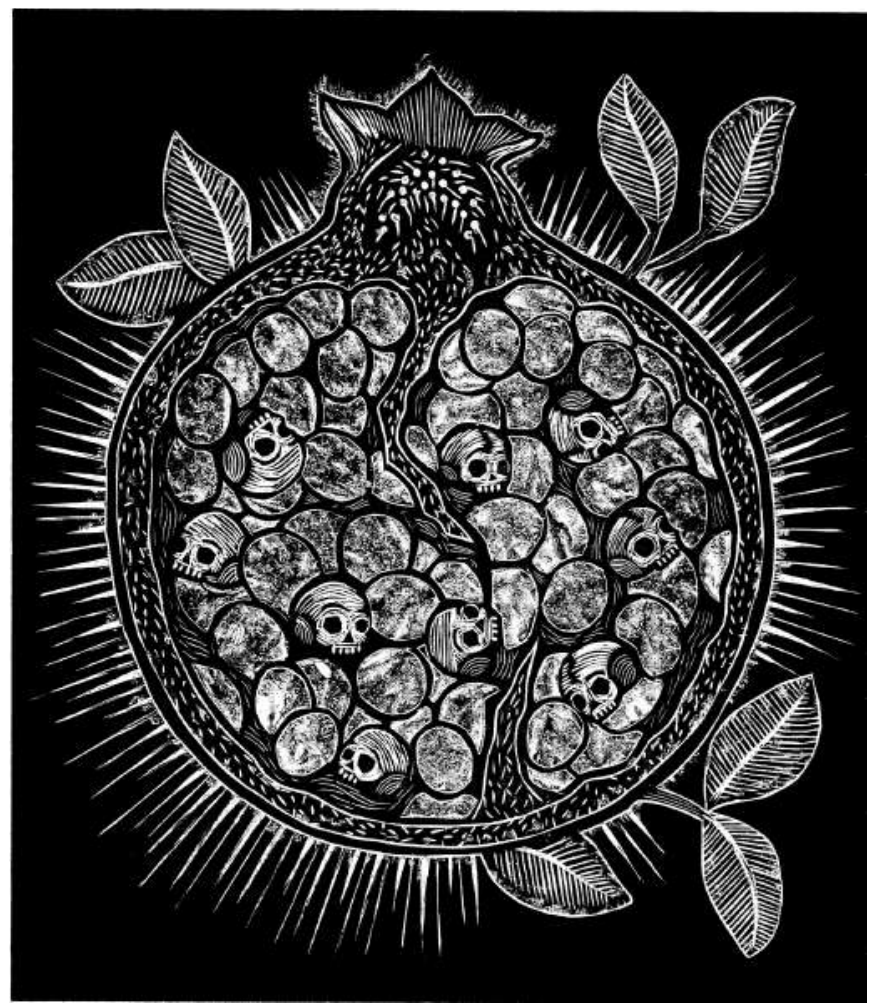

Brun. Granada. Xilografía. 63 x 69.5 cm, 2014

emulación y elogio.

La primera vez que tuve noticias del grabado hecho en Arequipa se produjo hace una década, en la 1. ${ }^{\text {a }}$ Bienal de Grabado del Icpna, mediante la exposición del taller "Lluvia de Sol”, que reunió el trabajo xilográfico de José Lara, Ysabel Clot, Rubén Mamani, Francy Cuentas, Abel Rimache, José Luis Pantigoso y su fundador, Luis Solorio, el único cuyo nombre conocía porque lo había descubierto como pintor en la Galería Cecilia González, en San Isidro, a fines de la década de los 90. Si podíamos situar temáticamente aquella pintura en la senda del indigenismo, esta ofrecía imágenes renovadas mediante el color, el encuadre de los paisajes andinos elegidos como locaciones para personajes que parecen existir coreográficamente y por el gran formato de sus telas. Campesinos, pastores, músicos y danzantes, vistos siempre desde lejos y generalmente en la cima de una montaña, eran sus personajes invariables, provenientes de la memoria de su infancia en Cusco y Puno, y a quienes reencontré, impresos, en aquella exhibición del Icpna de Miraflores.

Poco tiempo después, aquel taller, que en verdad había sido concebido como un centro de comercialización de papel artesanal para artistas, se desactivó y nunca más supe de él. Cuando viajé a Arequipa en octubre del 2010, alcancé a visitar la exposición individual de grabados de Ysabel Clot en la galería de la Alianza Francesa, pero no hallé ninguna alusión a "Lluvia de Sol".

En esa misma visita conocí, más bien, a artistas jóvenes, como Nereida Apaza y Raúl Chuquimia y pude obtener un ejemplar del primero de sus libros serigráficos. Ellos me hablaron de Tania Brun, la autora del segundo libro de esa colección notable que merecerá un comentario aparte en otro momento, y a quien conocí pocos meses después, cuando vino a Lima para que presentáramos aquella edición. Hasta ese momento, ninguno conocía a Luis Solorio, aunque vivían en la misma ciudad.

Sin embargo, todo cambió relativamente rápido: en el año 2013 no solo ya lo conocían, sino que habían sido sus alumnos y hacían grabado bajo su orientación sobre el papel artesanal que él continuaba haciendo para su propio uso.

Nereida Apaza (Arequipa, 1979), egresada con la "Medalla de Oro" de la Escuela Superior Pública "Carlos Baca Flor" de Arequipa, hasta ese momento había expuesto acuarelas y 


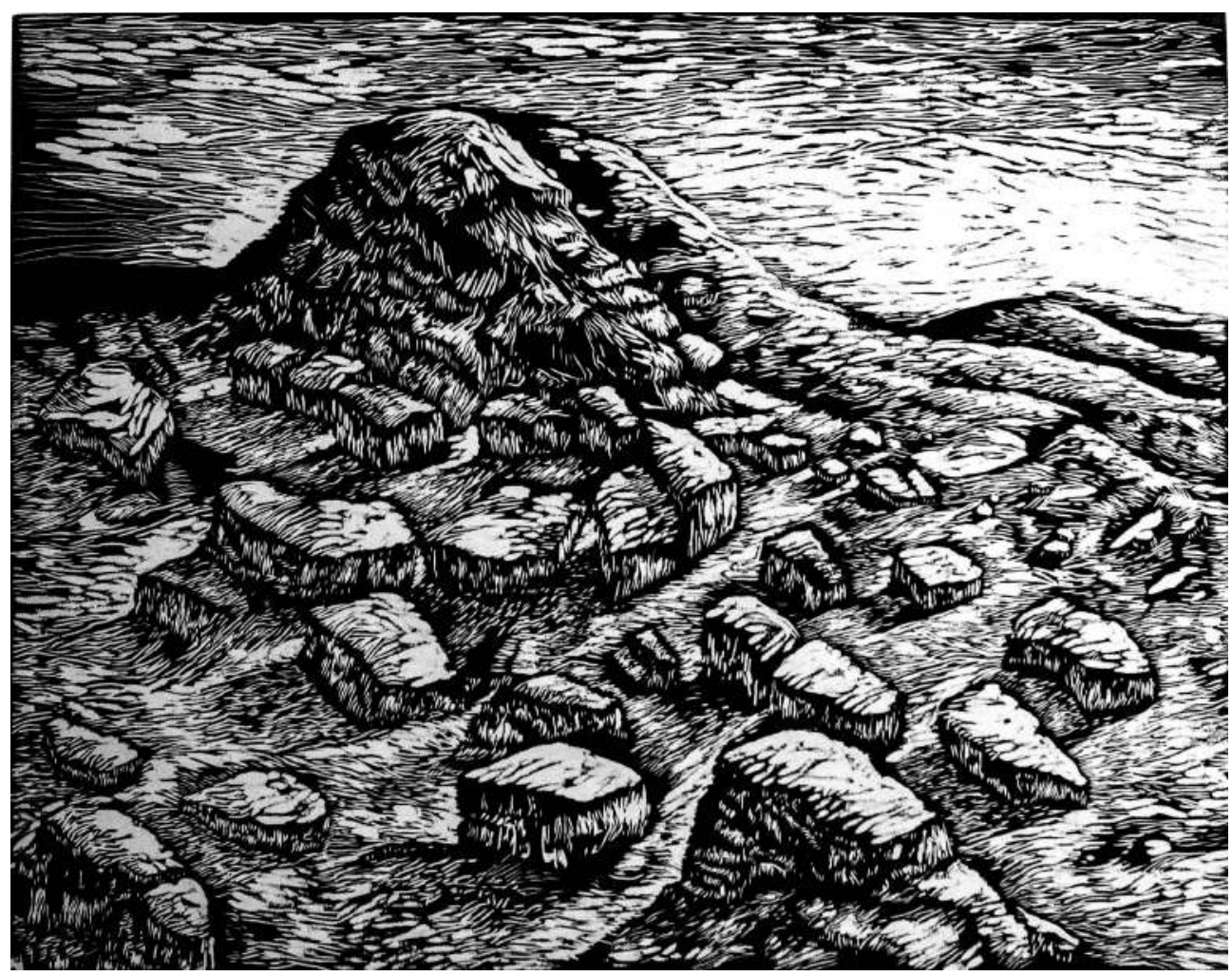

Gonzáles. Guardián Coropuna. Xilografía. 55 x 70 cm

objetos de naturaleza mixta palpablemente habitados por la poesía, pero no grabado. Tania Brun (Arequipa, 1982), por su parte, había hecho ilustraciones que se reproducían en revistas, fanzines, afiches y tapas de discos de bandas de rock, había incursionado en el estampado serigráfico de modo autodidacta desde 2008, pero practicaba la xilografía también a partir de un taller con Solorio. En el caso del mundo que ilustra Brun, ese herético y simpático elenco de personajes que pareciera disfrutar de su estadía en el averno, fue transferido sin problemas al grabado, tal como ocurrió con la serigrafía.

En julio del 2014, José Lara me envió a través de Eduardo Moll un catálogo de su extraordinaria muestra antológica de grabado titulado La ciudad de Lara, inaugurada un mes antes en el Museo de Arte Contemporáneo de Arequipa. La amable dedicatoria estaba escrita a mano sobre uno de los pliegos que me recordaban los del taller "Lluvia de Sol". El título de aquella muestra que reunía su obra grabada entre los años 1997 y 2013 fue un acierto, porque casi la totalidad de estampas contenía vistas urbanas en las que destacaba la singular arquitectura de Arequipa, es decir, fachadas y claustros de templos, plazas, mansiones, puentes, callejuelas antiguas y también las edificaciones nuevas y emergentes, como las que vemos en La manzana del cerro (2006). En este imaginario urbano casi no existe la presencia humana y se la detecta mediante la elocuencia de los espacios arquitectónicos.

Conocí a José Lara en su taller de la Escuela de Arte de la Universidad Nacional de San Agustín en Arequipa, recién a mediados del 2016. Allí me percaté de que el papel en que él y sus alumnos imprimían sus piezas solo podía ser producción de Luis Solorio, a quien pude conocer, por fin, durante ese breve paso por la ciudad. En aquella ocasión Solorio apareció 


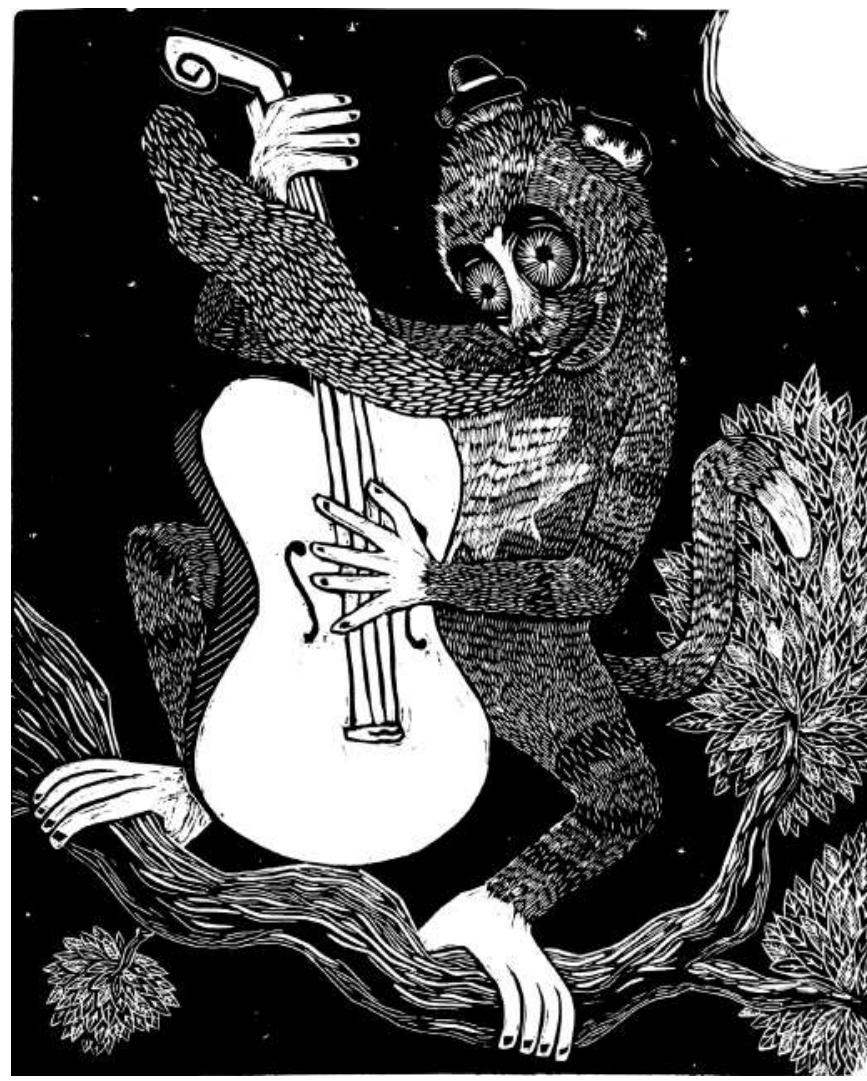

De Ybarra. Peludo de noche. Xilografía. 50.5 x 40.5 cm, 2013

en mi hotelito cargando un cartapacio enorme repleto de grabados de Abel Rimache, un artista que quería que yo conociera, quien, según me contó, lo había asistido en la elaboración de papel y había aprendido xilografía mirando su trabajo, calladito.

Abel Rimache (Arequipa, 1973) vive en Chivay, una localidad a dos horas de distancia de Arequipa, donde administra una tienda de objetos de arte y artesanía que se llama "Artes de Colca". Allí comercializa también sus grabados y unas libretas de papel que él elabora en Arequipa empleando el equipamiento de Solorio. No solo no tuvo una formación académica formal, y en su hoja de vida figura su experiencia como recluta del ejército y minero artesanal, sino que trabaja permanentemente en el campo ayudando a su madre agricultora. Debo agregar que es quechua hablante. Ese es el universo, inédito, que se asoma cada día con más claridad en sus estampas: danzantes, pastores, cóndores y personajes en escenas, a través de las cuales parece contar su propia vida.

Casi inmediatamente después conocí en Puno a Rubén Mamani (Arequipa, 1961), quien me recibió en el taller que tiene a su cargo como docente de la Escuela de Arte de la Universidad Nacional del Altiplano. Mamani es también pintor, pero es evidente que su medio connatural de trabajo actualmente es el grabado, al cual resuelve eventualmente en varios colores. Reconoce a Solorio, al igual que Lara, como un referente para su trabajo; y viaja a Arequipa, al igual que Rimache, para imprimir en su taller algunos de sus trabajos más grandes. Las estampas que hoy ejecuta Rubén Mamani representan paisajes, ritos y personajes altiplánicos, elementos de un universo aymara que ha hecho suyo mediante su vínculo matrimonial y su residencia de muchos años frente al lago Titicaca.

Finalmente, durante una visita a Toro Muerto en octubre del 2015, conocí a dos de los más jóvenes grabadores de esta breve selección ${ }^{3}$ : me refiero a Nathaly Gonzáles (Arequipa, 1984) y a Edward De Ybarra (Arequipa, 1988). Gonzáles, a quien reencontré como alumna de Lara el 2016, en la Universidad Nacional de San Agustín, asiste regularmente donde Solorio.

3 La que no estará completa, sin duda, hasta que no conozca a los egresados del taller de Grabado de la Escuela "Carlos Baca Flor". 
Ella participa también en varios colectivos artísticos y ejecuta música vernacular, vivencia que fue retratada en los grabados con los que egresó de la UNSA a fines de 2017. En sus piezas más recientes explora la cualidad telúrica del paisaje andino.

Edward De Ybarra estudió la Especialidad de Pintura en la ESFAP "Carlos Baca Flor" y la de Ciencias de la Comunicación en la Universidad Nacional de San Agustín. Desarrolló un trabajo creativo exclusivamente en cine y video, hasta que vio la exposición antológica que Luis Solorio presentó en el MAC de Arequipa en 2012, donde él se encontraba trabajando como catalogador. En el taller de Solorio se descubre como grabador $\mathrm{y}$, como tal, ha realizado exposiciones individuales. El mundo gráfico de Edward De Ybarra coincide con el Brun en pre-

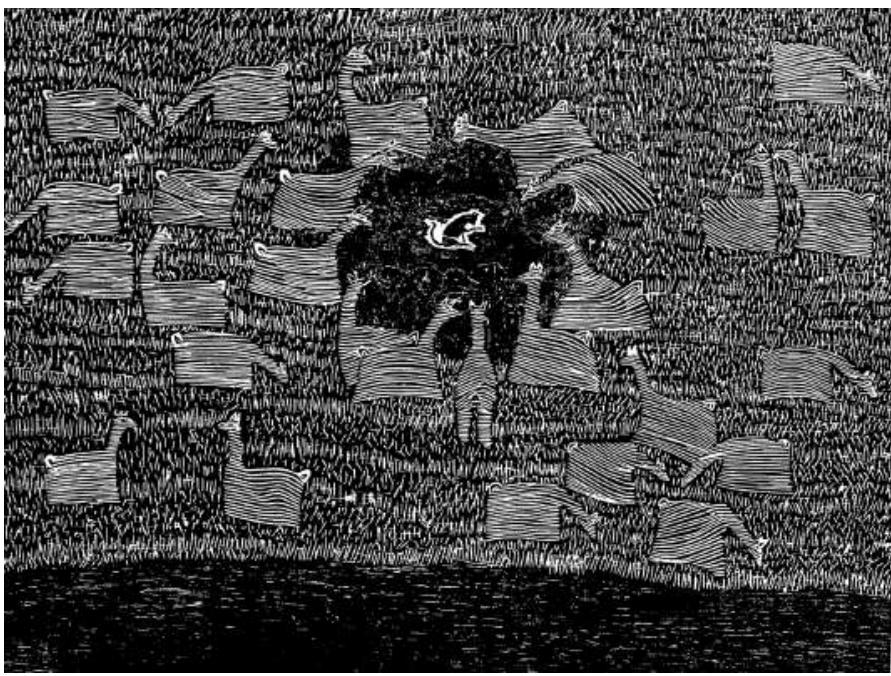

Rimache. Con su favorito. Xilografía. 45 x 60 cm, 2013

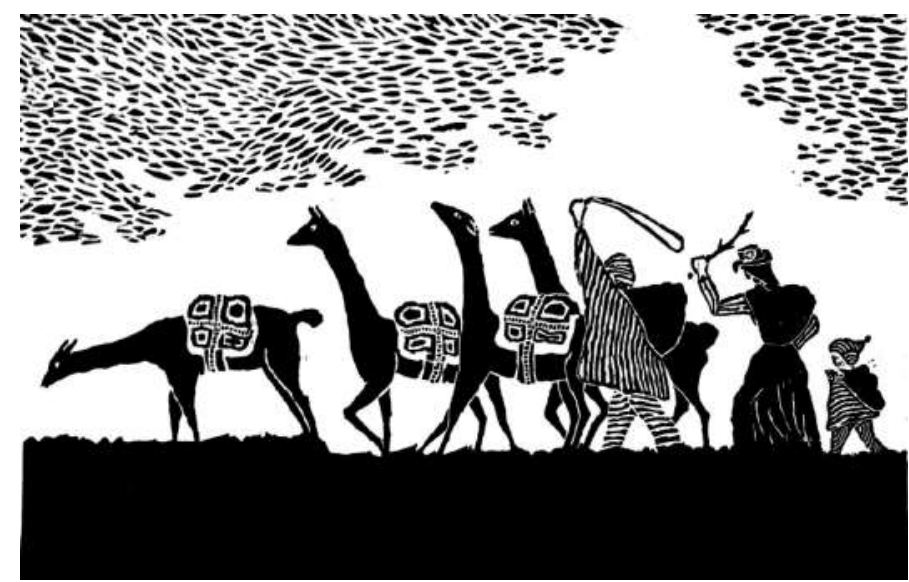

Rimache. La infancia de Abel. Xilografía. 40 x 64 cm, 2013 sentar también elencos de personajes entrañables, en su mayoría mamíferos "músicos" que disfrutan de vivir en una permanente fiesta, aunque también aparecen seres humanos perplejos ante sí mismos y su propia genitalidad.

Muy recientemente, la artista norteamericana Geneviève Guadalupe (Estados Unidos, 1968) se ha sumado a la lista de asiduos visitantes del taller de Luis Solorio. Guadalupe es bailarina y diseñadora de vestuario de ballet en su país, así como artista textil. Estudió, además, Dibujo y Grabado en The Drawing Studio, Arizona, y realizó grabado en metal. Durante sus estadías en Arequipa experimenta también con la xilografía, desarrollando una temática en la que la experiencia peruana va haciéndose patente.

Y como, en palabras de Rubén Mamani, “en lo que se refiere al grabado en Arequipa, todos los caminos conducen a Solorio", conviene que nos extendamos un poco sobre este artista, que parece convertir en grabadores a pintores, ilustradores e incluso a los autodidactas que ponen un pie en su taller de la Ciudad Blanca. 


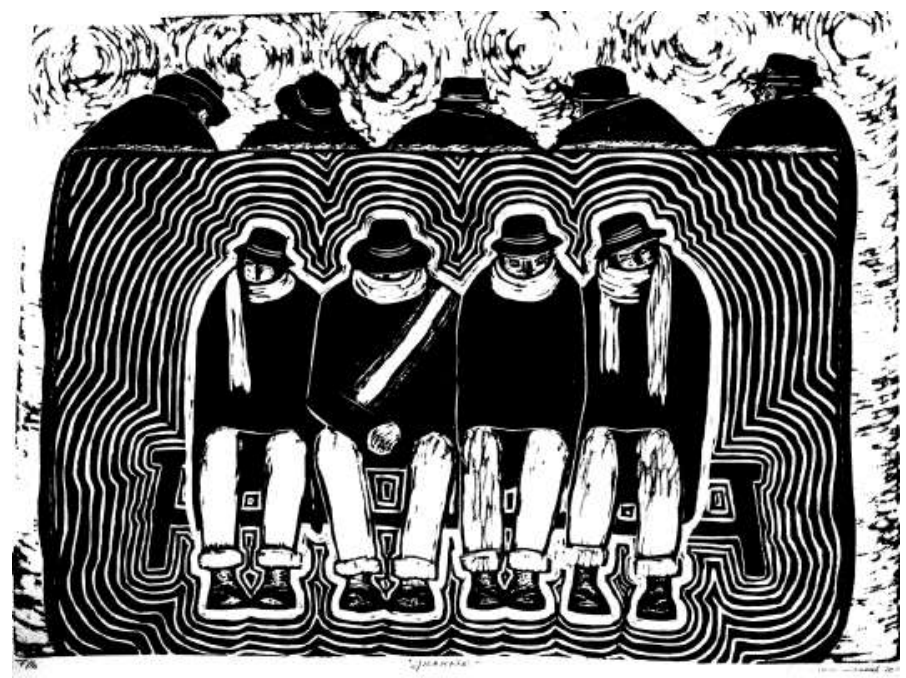

Rubén Mamani. Jilakatas. Xilografía. 50 x 66 cm, 2014

Luis Solorio nació en Sicuani, Cusco, en 1955 y pasó gran parte de su infancia y adolescencia en Juliaca, Puno. En Lima asistió al Taller de Dibujo de Cristina Gálvez y se formó como pintor $\mathrm{y}$ grabador en la Facultad de Artes Plásticas de la Universidad Católica del Perú. Se especializó en grabado en la École Superieure d'Arts Visuels de Ginebra, Suiza, y en el Taller Bigako de Tokio, Japón, donde investigó sobre la tradición del ukiyo-e. Asimismo, realizó estudios en el Basler Papiermühle de Basilea, Suiza. Expone individualmente desde 1982 en el Perú y en el extranjero.

\section{Colofón}

No podemos culpar de ingenuo si alguien, después de leer esa hoja de vida, nos pregunta: ¿Y por qué el señor Solorio no es profesor en una escuela de arte? Sin duda, debemos explicarle que en el Perú no es infrecuente que un artista con verdadero talento y que cuente con el respaldo de estudios de especialización en el extranjero, viajes y distinciones, sea mal visto por sus colegas en la enseñanza artística, y especialmente por aquellos que no encuentran otra expectativa que aferrarse a sus "horas lectivas", descuidando su vocación artística, si es que alguna vez la tuvieron.

Por último, debemos agregar que el señor Solorio sí enseñó en una escuela local y que, como el lector puede imaginar, prefirió regresar a la paz de su taller. Y esto, por lo que hemos visto, no solo fue bueno para su propia obra, incesante y prolífica, sino también para aquellos artistas que han encontrado en su espacio de trabajo un hospitalario lugar de aprendizaje y un laboratorio donde descubrir potencialidades creativas, pero, sobre todo, una lección de independencia sin precedentes.

¿Era posible que toda una "movida" gráfica se generase bajo la tutela y la generosidad de un solo artista? En Arequipa, al menos, Solorio lo ha conseguido, y sin proponérselo.

\section{Referencias bibliográficas}

Munive, M. (2015). Sortilegio. En Lundero, Suplemento cultural del diario "La Industria" Chiclayo - Trujillo (Perú), marzo de 2015, pp. 12 y 13.

Munive, M. (2018). A gravura contemporânea em Arequipa. Folleto. Ministerio de Relaciones Exteriores, Perú, junio-agosto 2018.
Ugarte Chocano, E. (2014). La ciudad de Lara. Exposición de grabado de José Lara. Museo de Arte Contemporáneo de Arequipa. Catálogo. La ciudad producciones, Arequipa, junio 2014. 


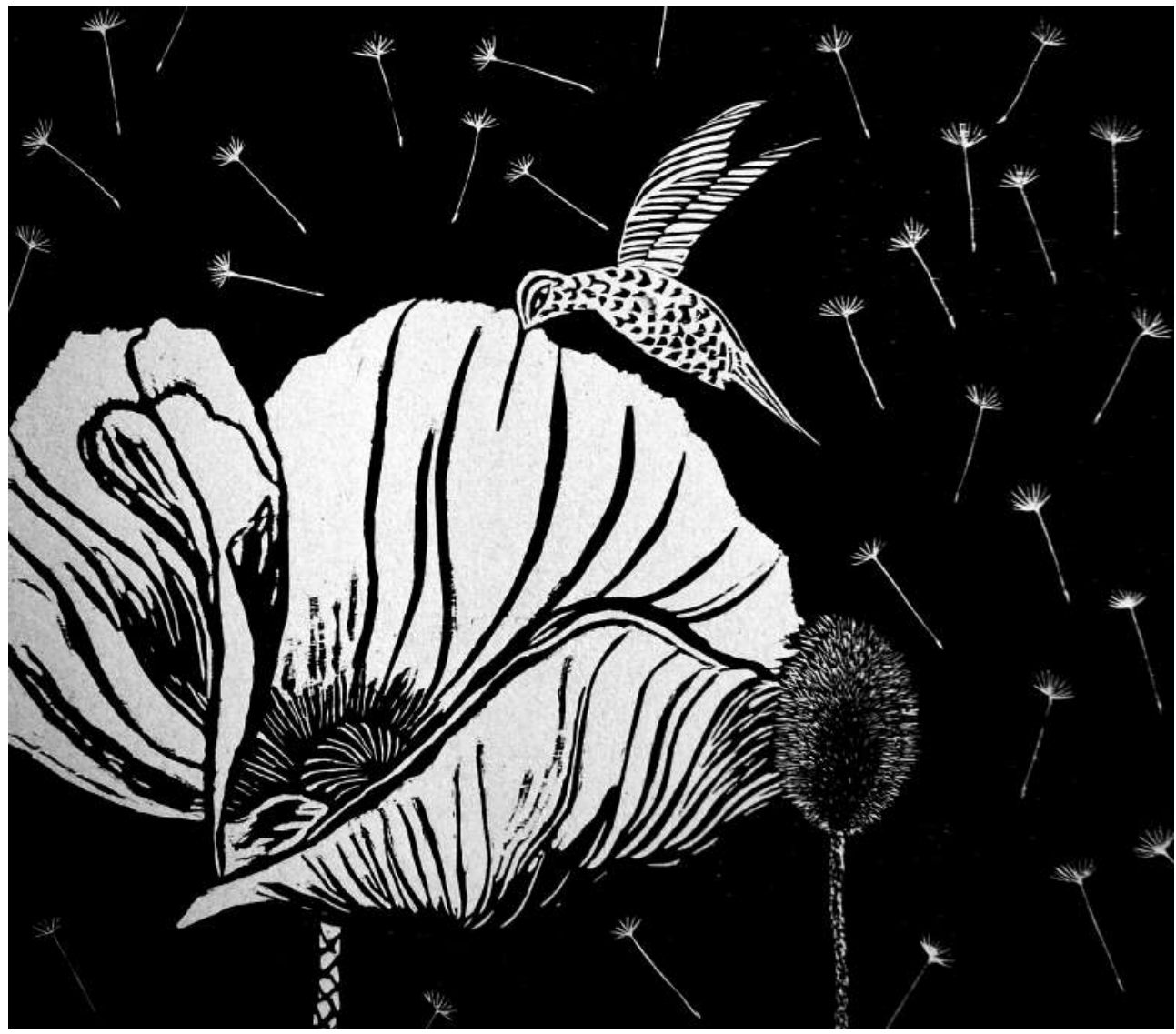

Guadalupe. Colibrí y su amapola. Xilografía, 43 x 53 cm, 2016

Recibido el 15 de setiembre del 2018

Aceptado el 30 de setiembre del 2018 